\title{
Efficiency of Thermal Management Using Phase-Change Material for Nonisothermal Adsorption Process
}

\section{AUTHOR(S):}

Sakanaka, Yuta; Hiraide, Shotaro; Tanaka, Hideki; Hiratsuka, Tatsumasa; Kojima, Natsuko; Yamane, Yasuyuki; Miyahara, Minoru T.

\section{CITATION:}

Sakanaka, Yuta ...[et al]. Efficiency of Thermal Management Using Phase-Change Material for Nonisothermal Adsorption Process. Industrial \& Engineering Chemistry Research 2020, 59(32): 14485-14495

\section{ISSUE DATE:}

2020-08-12

URL:

http://hdl.handle.net/2433/254352

\section{RIGHT:}

This document is the Accepted Manuscript version of a Published Work that appeared in final form in Industrial \& Engineering Chemistry Research, copyright @ American Chemical Society after peer review and technical editing by the publisher. To access the final edited and published work see https://doi.org/10.1021/acs.iecr.0c02344; The full-text file will be made open to the public on 19 July 2021 in accordance with publisher's 'Terms and Conditions for SelfArchiving'.; この論文は出版社版でありません。引用の際には出版社版をご確認ご利用ください。; This is not the published version. Please cite only the published version. 


\section{Efficiency of thermal management using phase-}

\section{change material for nonisothermal adsorption}

\section{process}

Yuta Sakanaka, ${ }^{1}$ Shotaro Hiraide, ${ }^{1, *}$ Hideki Tanaka,${ }^{2}$ Tatsumasa Hiratsuka, ${ }^{1}$ Natsuko Kojima, ${ }^{3}$ Yasuyuki Yamane $e^{3}$ and Minoru T. Miyahara ${ }^{1, *}$

${ }^{1}$ Department of Chemical Engineering, Kyoto University, Nishikyo, Kyoto 615-8510, Japan

${ }^{2}$ Research Initiative for Supra-Materials (RISM), Shinshu University, 4-17-1 Wakasato, Nagano 380-8553, Japan

${ }^{3}$ Innovation \& Development Department, Activated Carbon Business Division, Osaka Gas

Chemicals Co., Ltd., 5-11-61, Torishima, Konohana-ku, Osaka, 554-0051, Japan 


\section{ABSTRACT}

Current energy issues have driven the development of high-throughput separation processes using solid adsorbents as an alternative to distillation. However, it is a crucial problem that the temperature increase due to the adsorption heat significantly reduces the adsorption performance because of near adiabatic operations. Herein, we discuss thermal management using phase change materials (PCMs) in such processes based on a combination of experimental and theoretical studies. Breakthrough curve measurements for $n$-butane adsorption on a packed bed column containing activated carbon and PCM pellets confirm the validity of our nonisothermal adsorption column model that considers the latent heat of fusion of PCMs. Then, the effects of the melting temperature and weight fraction of PCMs on adsorption performance are thoroughly investigated for an adiabatic adsorption process. Finally, we propose a simple heat balance equation for the optimum weight fraction of PCMs that maximizes the adsorption capacity of the column.

\section{INTRODUCTION}

Given the current energy situation, it has become an urgent task to change the separation process for gas mixtures from methods, such as distillation, that rely on thermal energy to low-energy approaches using solid adsorbents or membranes. ${ }^{1}$ Pressure swing adsorption (PSA) is a wellknown process for gas separation. Many studies to improve its productivity have been conducted in a wide range of fields, including $\mathrm{CO}_{2}$ separation ${ }^{2}$ and volatile organic compounds separation. ${ }^{3}$ Rapid PSA technology, in which the total cycle time of the PSA process is reduced to decrease the bed size factor (the amount of adsorbent required to produce a unit quantity of the product in unit time), is a successful example of these attempts. ${ }^{4-5}$ However, this type of strategy for achieving 
high-throughput separation through the PSA process, including simply enlarging the system size, ${ }^{6}$ tends to make the system near adiabatic. Therefore, the heat of adsorption plays an important role in such processes because the adsorbed amount decreases as the temperature increases. ${ }^{7-8}$ Yang and Cen compared a PSA process for $\mathrm{CH}_{4} / \mathrm{H}_{2}$ separation using activated carbon under adiabatic conditions to that under isothermal conditions. ${ }^{7}$ In adiabatic conditions, the equilibrium capacity decreased due to the temperature increase of approximately $40 \mathrm{~K}$, which resulted in a $25.5 \%$ reduction in $\mathrm{CH}_{4}$ recovery compared to isothermal conditions. In light of this fact, applying a heat exchange system to a PSA process is effective in increasing the throughput capability of PSA. In particular, thermal energy storage (TES) systems are suitable for the PSA process because when they are heated during the adsorption process, they can be used as the heat source for desorption. The TES system cools during the desorption process, allowing it to act as a heat sink in the adsorption process, and this cycle repeats.

There are three types of TES systems that use sensible heat, latent heat, and chemical reaction heat. ${ }^{9}$ Among them, the systems using sensible heat or latent heat do not affect the adsorption behavior and can be used in cyclic operation. Vasiliev et al. demonstrated that the temperature of a gas storage column could be efficiently controlled by inserting aluminum panels as a sensible heat storage material. ${ }^{10}$ In addition, several studies have reported sensible heat type TES systems using water, rock beds, and molten salt. ${ }^{11-12}$ Recently, latent heat type TES systems using phase change materials (PCMs) have attracted considerable attention owing to their larger energy storage capacity per volume and temperature change than sensible heat type TES.${ }^{13}$ For example, rubber balls encapsulating organic materials ${ }^{14}$ and copper tubes containing a mixture of fatty acids ${ }^{15}$ have been reported as PCMs for adsorption processes. Furthermore, several studies have demonstrated that heat suppression efficiency can be improved by inserting PCMs inside adsorbents to shorten 
the heat transfer distance. ${ }^{16-17}$ As a commercial product, a series of phenolic resin pellets that contain microcapsules filled with paraffin wax is available from Osaka Gas Chemicals. ${ }^{18}$ The beneficial feature of these materials is that the melting temperature can be easily changed by changing the type of paraffin wax contained in it. While the applications for these products are currently limited to automotive canisters, they could also be useful in various adsorption processes, such as PSA.

Integrating PCM into the adsorption column would suppress the temperature change of adsorbents and improve the adsorption capacity of the adsorbent. However, at the same time, the PCM occupies a certain space in the column and reduces the amount of adsorbent with which it can be packed. Therefore, there should be an optimum weight fraction for PCMs that maximizes the throughput capacity of the column. When investigating this factor, it is effective to use numerical simulations that can not only change parameters without material limitations but also obtain values that cannot be measured experimentally.

Numerical simulations of adsorption processes have been widely performed based on a onedimensional column model consisting of material and heat balances. ${ }^{19-26}$ Kim et al. investigated a two-column PSA system for landfill gas separation using a carbon molecular sieve. ${ }^{21}$ They simulated a PSA process for a $\mathrm{CO}_{2} / \mathrm{CH}_{4}$ gas mixture under isothermal conditions, adiabatic conditions, and nonisothermal conditions that were determined based on breakthrough experiments and demonstrated that it is essential to consider the temperature increase due to the heat of adsorption in a column simulation. Lopes et al. calculated a vacuum PSA process for hydrogen separation from reformed gas using activated carbon and demonstrated that an extended virial isotherm using parameters for single-component gas adsorption succeeded in predicting multicomponent gas adsorption behavior. ${ }^{23}$ Casas et al. examined $\mathrm{CO}_{2} / \mathrm{N}_{2}$ adsorption on activated 
carbon under high-pressure conditions and developed a model that could reproduce experimental breakthrough curves at various pressures, feed gas components, and flow rates. ${ }^{25}$ These studies indicate that the one-dimensional column model is suitable for describing the observed adsorption behavior but that the model should be constructed to accommodate nonisothermal behavior by taking the effects of the heat of adsorption into account.

TES systems using PCMs have also been investigated using numerical simulations. ${ }^{27-30}$ Schumann developed a two-phase model wherein the temperatures of the PCMs and heat transfer fluid were considered separately. ${ }^{27}$ A simplified calculation treating the system temperature as homogeneous ${ }^{28}$ and an extended Schumann's model considering the temperature distribution inside a $\mathrm{PCM}^{29}$ were also developed. While most of these studies have focused on the heat exchange between the PCMs and heat transfer fluid, few numerical simulations on PCMs in the adsorption process have been reported..$^{16-17}$

In the present study, we measured the breakthrough curves and temperature distributions of a packed bed column for $n$-butane adsorption containing activated carbon and PCM pellets and developed a one-dimensional column model considering the heat transfer between the adsorbent and PCM. The effects that the weight fraction and melting temperature of PCM have on the adiabatic adsorption process, which occurs in extreme conditions in a high-throughput adsorption process, were evaluated using the developed column model. This investigation provided insight into how PCM works during the adsorption process and served as the first step in constructing a PSA system incorporating sensible heat-type TES.

\section{EXPERIMENTAL SECTION}




\subsection{Materials}

Activated carbon pellets with a length of $3 \mathrm{~mm}$ and a diameter of $2 \mathrm{~mm}$ were provided by Osaka Gas Chemicals. PCM pellets (PCM36G-AC) of the same shape and size as the activated carbon pellets were also supplied by Osaka Gas Chemicals. Figure 1 shows the schematic illustration of PCM36G-AC, which contains 72 wt $\%$ of microcapsules filled with paraffin wax. The melting temperature of the paraffin wax inside the PCM36G-AC was $305 \mathrm{~K}$, which was characterized by differential scanning calorimetry (Figure S1, Supporting Information). Note that the PCM pellets were non-porous (Figure S2).

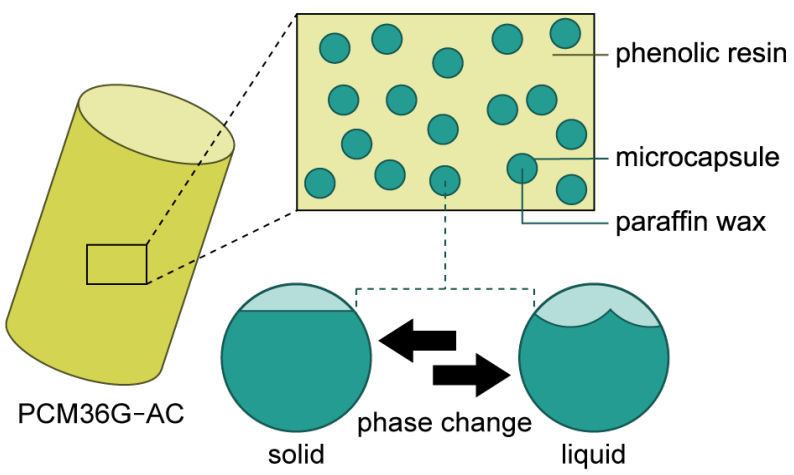

Figure 1 Schematic illustration of the PCM pellet used in this study. Microcapsules containing paraffin wax are dispersed in phenolic resin.

\subsection{Adsorption isotherm measurements}

The adsorption isotherms of $n$-butane and $\mathrm{N}_{2}$ on the activated carbon pellets at 283, 298, and 313 K were obtained using a BELSORP-max (MicrotracBEL Co.). The adsorbent was activated by heating at $423 \mathrm{~K}$ for $3 \mathrm{~h}$ under a vacuum before each measurement. 


\subsection{Breakthrough curve measurements}

Breakthrough curves were measured using a lab-made apparatus consisting of two mass flow controllers (MFC) (SEC-N112MGRW, HORIBA), static mixer, adsorption column, bypass flow path, quadrupole mass spectrometer (QMS) (M-101QA-TDM, CANON ANELVA), and thermostatic oven. The flowsheet of the apparatus is illustrated in Figure 2. The adsorption column made of SUS316 with a thickness of $2 \mathrm{~mm}$ had a length of $15 \mathrm{~cm}$ and inner diameter of $1 \mathrm{~cm}$. The well-mixed activated carbon and PCM pellets were placed in the adsorption columns and activated under $\mathrm{N}_{2}$ flow at $423 \mathrm{~K}$ for $3 \mathrm{~h}$. The adsorption columns were then purged with $100 \mathrm{kPa}$ of pure $\mathrm{N}_{2}$, and an $n$-butane/ $\mathrm{N}_{2}$ gas mixture flowed through the bypass flow path. Then, the feed stream was switched from the bypass channel to the adsorption columns side, and the gas composition downstream of the adsorption column was measured using QMS. The observed pressure drop was negligible (approximately $4 \mathrm{kPa}$ ). The temperatures of the packed bed were also measured 5.5, 7.5, and $9.5 \mathrm{~cm}$ away from the column inlet. We conducted six breakthrough measurements by varying the weight fraction of the PCM, flow rate of the feed, and $n$-butane fraction of the feed, as summarized in Table 1 . The adsorbent was regenerated before each experiment under $\mathrm{N}_{2}$ flow at $423 \mathrm{~K}$ for $1 \mathrm{~h}$. The ambient temperature was controlled at $303 \mathrm{~K}$. The QMS was calibrated using certified $n$-butane/ $\mathrm{N}_{2}$ gas mixtures before the measurements. 


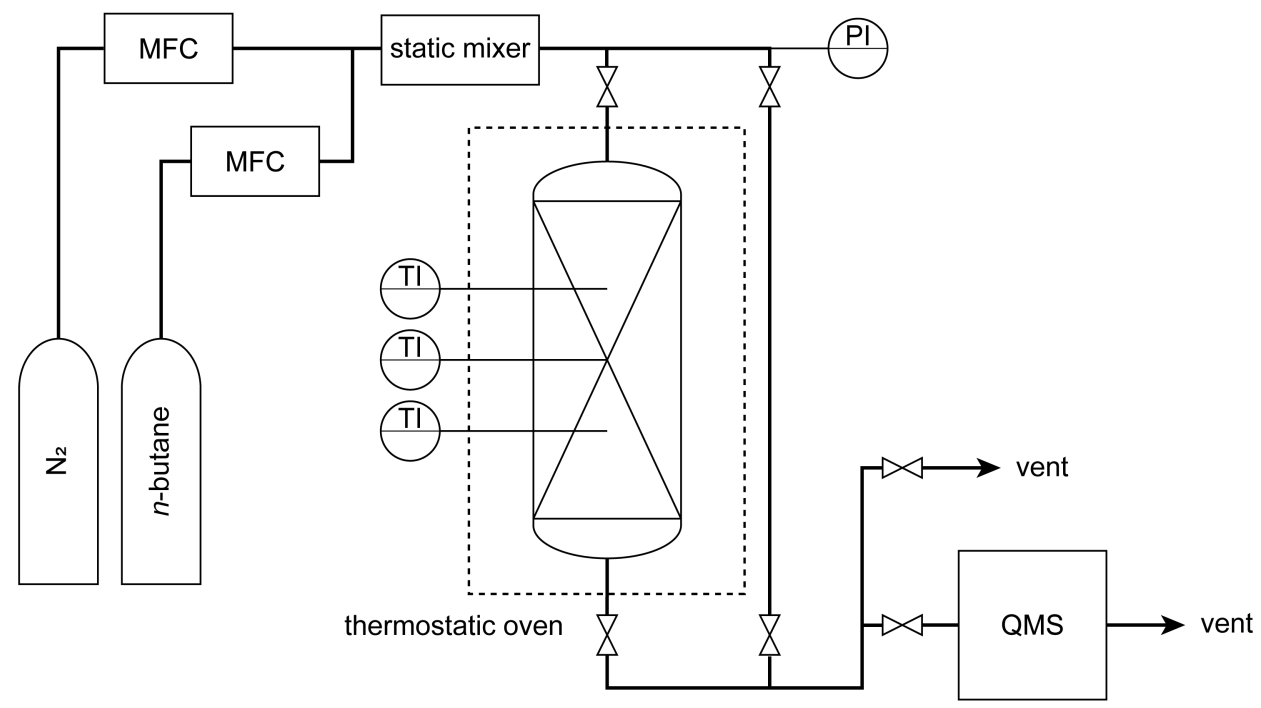

Figure 2 Flowchart of the apparatus for breakthrough measurements. The adsorption column has a length of $15 \mathrm{~cm}$ and an inner diameter of $1 \mathrm{~cm}$. Three thermocouples were placed 5.5, 7.5, and $9.5 \mathrm{~cm}$ from the column inlet.

Table 1 Conditions of breakthrough experiments

\begin{tabular}{cccccc}
\hline Condition & $\begin{array}{c}\text { Bed density of } \\
\text { activated carbon } \\
\text { and PCM } \\
{[\mathrm{kg}-}\end{array}$ & $\begin{array}{c}\text { Weight fraction } \\
\text { of PCM } \\
{\left[\mathrm{kg}-\mathrm{PCM} \cdot \mathrm{kg}_{-}\right.} \\
\left.(\mathrm{AC} \& \mathrm{PCM}) \cdot \mathrm{m}^{-3}\right]\end{array}$ & $\begin{array}{c}\left.\text { Flow rate of })^{-1}\right] \\
\text { feed gas }^{\mathrm{a}} \\
{\left[\mathrm{sccm}^{\mathrm{b}}\right]}\end{array}$ & $\begin{array}{c}n \text {-butane } \\
\text { fraction of } \\
\text { feed gas } \\
{[-]}\end{array}$ & $\begin{array}{c}\text { Ambient } \\
\text { temperature } \\
{[\mathrm{K}]}\end{array}$ \\
\hline A & 313 & 0 & $70(0.016)$ & 0.5 & 303 \\
B & 328 & 0.33 & $70(0.016)$ & 0.5 & 303 \\
\hline C & 313 & 0 & $70(0.016)$ & 0.25 & 303 \\
D & 313 & 0 & $140(0.032)$ & 0.5 & 303 \\
E & 328 & 0.33 & $70(0.016)$ & 0.25 & 303 \\
F & 328 & 0.33 & $140(0.032)$ & 0.5 & 303 \\
\hline
\end{tabular}



K.

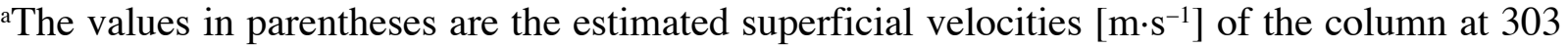

${ }^{\mathrm{b}} \mathrm{sccm}:$ standard $\mathrm{cm}^{3} \cdot \mathrm{min}^{-1}$

\section{SIMULATION METHODS}

\subsection{Column model}

\subsubsection{Material and energy balances}

We developed a one-dimensional nonisothermal column model to describe the adsorption behavior in the column. The following assumptions were made:

- Radial direction profiles are neglected.

- Mass transfer resistance is described using a linear driving force model.

- Temperature dependence of mass transfer constant, heat of adsorption, and heat capacity are neglected.

- The temperatures of the gas phase, adsorbent, and phenolic resin of PCM are uniform as the bed temperature $T_{\mathrm{B}}$, while the temperature of paraffin wax inside PCM pellets is described using a separate variable $T_{\mathrm{PW}}$.

Based on these assumptions, the material balance of species $i$ is expressed as:

$$
\begin{gathered}
\varepsilon_{\mathrm{T}} \frac{\partial c_{i}}{\partial t}=-\frac{\partial J_{i}}{\partial z}-\rho_{\mathrm{B}}\left(1-\phi_{\mathrm{PCM}}\right) \frac{\partial n_{i}}{\partial t} \\
J_{i}=u c_{i}-\varepsilon_{\mathrm{B}} c D_{\mathrm{L}} \frac{\partial y_{i}}{\partial z}
\end{gathered}
$$

where $\varepsilon_{\mathrm{T}}$ is the overall void fraction, $c_{i}$ is the gas phase concentration of $i, J_{i}$ is the mole flux of $i$, $\rho_{\mathrm{B}}$ is the total bed density of activated carbon and PCM, $\phi_{\mathrm{PCM}}$ is the weight fraction of PCM, $n_{i}$ is the amount of adsorbed $i, u$ is the superficial gas velocity, $\varepsilon_{\mathrm{B}}$ is the bed void fraction, $c$ is the total 
concentration of the gas phase, $y_{i}$ is the mole fraction of $i, t$ is the time, and $z$ represents the space coordinates. $D_{\mathrm{L}}$ is the axial dispersion coefficient described by the following equation. ${ }^{25}$

$$
D_{\mathrm{L}}=0.7 D_{\mathrm{m}}+0.5 d_{\mathrm{p}} \frac{u}{\varepsilon_{\mathrm{T}}}
$$

where $D_{\mathrm{m}}$ is the molecular diffusion coefficient and $d_{\mathrm{p}}$ is the Sauter mean diameter of the pellet. According to the linear driving force model, the adsorption rate can be written as:

$$
\frac{\partial n_{i}}{\partial t}=k_{i}\left(n_{i}^{*}-n_{i}\right)
$$

where $k_{i}$ and $n_{i}^{*}$ are the adsorption rate constant and amount of adsorbed $i$ at equilibrium, respectively.

The energy balance for the gas phase, adsorbent, and phenolic resin of PCM can be written as follows.

$$
\begin{gathered}
{\left[\varepsilon_{\mathrm{T}} \sum_{i} c_{i} C_{\mathrm{p}, i}+\rho_{\mathrm{B}}\left(1-\phi_{\mathrm{PCM}}\right) C_{\mathrm{p}, \mathrm{AC}}+\rho_{\mathrm{B}} \phi_{\mathrm{PCM}}\left(1-\theta_{\mathrm{PW}}\right) C_{\mathrm{p}, \mathrm{PR}}+\right.} \\
\left.\rho_{\mathrm{B}}\left(1-\phi_{\mathrm{PCM}}\right) \sum_{i} n_{i} C_{\mathrm{p}, i}\right] \frac{\partial T_{\mathrm{B}}}{\partial t}-\varepsilon_{\mathrm{T}} \frac{\partial p}{\partial t}=-\sum_{i} J_{i} C_{\mathrm{p}, i} \frac{\partial T_{\mathrm{B}}}{\partial t}+\rho_{\mathrm{B}}(1- \\
\left.\phi_{\mathrm{PCM}}\right)\left(-\Delta H_{\mathrm{ads}, i}\right) \frac{\partial n_{i}}{\partial t}+\varepsilon_{\mathrm{B}} \lambda_{\mathrm{B}} \frac{\partial^{2} T_{\mathrm{B}}}{\partial \mathrm{z}^{2}}+\rho_{\mathrm{B}} \phi_{\mathrm{PCM}} U_{\mathrm{BPW}}\left(T_{\mathrm{PW}}-T_{\mathrm{B}}\right)+ \\
\frac{2}{r_{\mathrm{i}}} h_{\mathrm{BW}}\left(T_{\mathrm{W}}-T_{\mathrm{B}}\right)
\end{gathered}
$$

where $C_{\mathrm{p}, i}, C_{\mathrm{p}, \mathrm{AC}}$, and $C_{\mathrm{p}, \mathrm{PR}}$ are the heat capacities of gas $i$, activated carbon, and phenolic resin of $\mathrm{PCM}$, respectively; $\theta_{\mathrm{PW}}$ is the weight fraction of paraffin wax in PCM; $p$ is the pressure; $\Delta H_{\mathrm{ads}, i}$ is the isosteric heat of the adsorption of $i ; \lambda_{\mathrm{B}}$ is the axial thermal conductivity of the packed bed; $U_{\mathrm{BPW}}$ is the overall heat transfer coefficient between the packed bed and the paraffin wax; $h_{\mathrm{BW}}$ is the heat transfer coefficient between the packed bed and the column wall; $r_{\mathrm{i}}$ is the inner radius of the column; and $T_{\mathrm{W}}$ is the temperature of the column wall. The energy balance for the column wall is given by: 


$$
C_{\mathrm{p}, \mathrm{W}} \frac{\partial T_{\mathrm{W}}}{\partial t}=\lambda_{\mathrm{W}} \frac{\partial^{2} T_{\mathrm{W}}}{\partial z^{2}}+\frac{2 \pi}{a_{\mathrm{W}}}\left[r_{\mathrm{i}} h_{\mathrm{BW}}\left(T_{\mathrm{B}}-T_{\mathrm{W}}\right)-r_{\mathrm{o}} h_{\mathrm{WA}}\left(T_{\mathrm{A}}-T_{\mathrm{W}}\right)\right],
$$

where $C_{\mathrm{p}, \mathrm{W}}$ is the heat capacity of the wall, $\lambda_{\mathrm{w}}$ is the axial thermal conductivity of the wall, $a_{\mathrm{w}}$ is the cross-sectional area of the wall, $r_{\mathrm{o}}$ is the outer radius of the column, $h_{\mathrm{WA}}$ is the heat transfer coefficient between the wall and the environment, and $T_{\mathrm{A}}$ is the ambient temperature. The energy balance of the PCM paraffin wax is described as:

$$
\theta_{\mathrm{PW}} \frac{\partial H_{\mathrm{PW}}}{\partial t}=U_{\mathrm{BPW}}\left(T_{\mathrm{B}}-T_{\mathrm{PW}}\right)
$$

where $H_{\mathrm{PW}}$ is the enthalpy of paraffin wax.

We applied the Robin boundary condition at the column inlet and the Neumann boundary condition at the column outlet:

For the inlet: $z=0$

$$
\begin{gathered}
u^{\text {feed }} c_{i}^{\text {feed }}=u c_{i}-\varepsilon_{\mathrm{B}} D_{\mathrm{L}} c \frac{\partial y_{i}}{\partial z}, \\
\sum_{i} u^{\text {feed }} c_{i}^{\text {feed }} H_{i}^{\text {feed }}=\sum_{i} J_{i} H_{i}-\varepsilon_{\mathrm{B}} \lambda_{\mathrm{B}} \frac{\partial T_{\mathrm{B}}}{\partial \mathrm{z}}, \\
\frac{\partial T_{\mathrm{W}}}{\partial z}=0 .
\end{gathered}
$$

For the outlet: $z=L$

$$
\begin{gathered}
\frac{\partial c_{i}}{\partial z}=0, \\
\frac{\partial T_{\mathrm{B}}}{\partial z}=\frac{\partial T_{\mathrm{W}}}{\partial z}=0, \\
p=p_{\text {out }} .
\end{gathered}
$$

The initial conditions of the fluid concentration and each temperature are given as follows.

$$
\begin{gathered}
c=c_{\mathrm{N}_{2}}, \quad c_{n \text {-butane }}=0, \\
T_{\mathrm{B}}=T_{\mathrm{PW}}=T_{\mathrm{W}}=T_{\mathrm{A}} .
\end{gathered}
$$




\subsubsection{Equation of state}

The ideal gas law was used to describe gas phase behavior:

$$
c_{i}=\frac{y_{i} p}{R T_{\mathrm{B}}}
$$

where $R$ is the gas constant.

\subsubsection{Adsorption isotherm model}

The Sips equation was used to represent the amount of adsorbed $i$ at equilibrium:

$$
n_{i}^{*}=n_{\mathrm{s}, i} \frac{\left(b_{i} p\right)^{\frac{1}{s_{i}}}}{1+\left(b_{i} p\right)^{\frac{1}{s_{i}}}},
$$

where $n_{\mathrm{s}, i}$ is the saturation capacity, $b_{i}$ is the affinity constant, and $s_{i}$ is the Sips constant characterizing the heterogeneity of the adsorbent surface. The following equations represent the temperature dependence of each parameter:

$$
\begin{gathered}
n_{\mathrm{s}, i}=n_{\mathrm{sref}, i} \exp \left[\chi_{i}\left(1-\frac{T_{\mathrm{B}}}{T_{\mathrm{ref}}}\right)\right], \\
b_{i}=b_{\mathrm{ref}, i} \exp \left[\frac{Q_{i}}{R T_{\mathrm{ref}}}\left(\frac{T_{\mathrm{ref}}}{T_{\mathrm{B}}}-1\right)\right], \\
\frac{1}{s_{i}}=\frac{1}{s_{\mathrm{ref}, i}}+\alpha_{i}\left(1-\frac{T_{\mathrm{ref}}}{T_{\mathrm{B}}}\right)
\end{gathered}
$$

where $n_{\text {sref }, i}, b_{\text {ref }, i}$, and $s_{\text {ref }, i}$ are the values of $n_{\mathrm{s}, i}, b_{i}$, and $s_{i}$ at the reference temperature $T_{\text {ref }} ; \chi_{i}$ and $\alpha_{i}$ are constant parameters; and the constant parameter $Q_{i}$ refers to the isosteric heat when the fractional loading is 0.5 .

\subsubsection{Pressure drop}

The superficial gas velocity, $u$, was calculated by solving the Ergun equation described as follows: 


$$
\frac{\partial p}{\partial z}=-\frac{150 \mu\left(1-\varepsilon_{\mathrm{B}}\right)^{2}}{\varepsilon_{\mathrm{B}}^{3} d_{\mathrm{p}}^{2}} u-\frac{1.75\left(1-\varepsilon_{\mathrm{B}}\right) \rho}{\varepsilon_{\mathrm{B}}^{3} d_{\mathrm{p}}}|u| u,
$$

where $\mu$ and $\rho$ are the dynamic viscosity and density of the fluid, respectively.

\subsubsection{Temperature dependence of enthalpy of paraffin wax}

The relationship between the temperature and enthalpy of paraffin wax depends on whether the paraffin wax is in the solid phase $\left(T_{\mathrm{PW}}<T_{\mathrm{m}}, T_{\mathrm{m}}\right.$ is the melting temperature $)$, liquid phase $\left(T_{\mathrm{PW}}>\right.$ $\left.T_{\mathrm{m}}\right)$, or melting phase $\left(T_{\mathrm{PW}}=T_{\mathrm{m}}\right)$. To simplify the calculation, the temperature dependence of the paraffin wax enthalpy was described by the following equation, ${ }^{31}$ which includes an artificial parameter, $\Delta T_{\mathrm{m}}$, to make a one-to-one comparison:

$$
\begin{gathered}
H_{\mathrm{PW}}= \\
\left\{\begin{array}{c}
H_{\mathrm{ref}, \mathrm{PW}}+C_{\mathrm{p}, \mathrm{PW}}^{\mathrm{s}}\left(T_{\mathrm{PW}}-T_{\mathrm{ref}}\right) \quad\left(T_{\mathrm{PW}} \leq T_{\mathrm{m}}\right) \\
H_{\mathrm{ref}, \mathrm{PW}}+C_{\mathrm{pPW}}^{\mathrm{s}}\left(T_{\mathrm{m}}-T_{\mathrm{ref}}\right)+\frac{\Delta H_{\mathrm{PW}}}{\Delta T_{\mathrm{m}}}\left(T_{\mathrm{PW}}-T_{\mathrm{m}}\right) \quad\left(T_{\mathrm{m}}<T_{\mathrm{PW}} \leq T_{\mathrm{m}}+\Delta T_{\mathrm{m}}\right) \\
H_{\mathrm{ref}, \mathrm{PW}}+C_{\mathrm{pPW}}^{\mathrm{s}}\left(T_{\mathrm{m}}-T_{\mathrm{ref}}\right)+\Delta H_{\mathrm{PW}}+C_{\mathrm{p}, \mathrm{PW}}^{\mathrm{l}}\left[T_{\mathrm{PW}}-\left(T_{\mathrm{m}}+\Delta T_{\mathrm{m}}\right)\right] \quad\left(T_{\mathrm{m}}+\Delta T_{\mathrm{m}}<T_{\mathrm{PW}}\right)
\end{array}\right.
\end{gathered}
$$

where $H_{\text {ref,Pw }}$ is the enthalpy of paraffin wax at the reference temperature $T_{\text {ref }}, C_{\mathrm{p}, \mathrm{PW}}{ }^{\mathrm{s}}$ and $C_{\mathrm{p}, \mathrm{PW}}{ }^{1}$ are the heat capacities of paraffin wax in the solid and liquid phases, respectively, $\Delta H_{\mathrm{PW}}$ is the latent heat of paraffin wax, and $\Delta T_{\mathrm{m}}$ is a small value that makes the gradient of $H_{\mathrm{PW}}$ to $T_{\mathrm{PW}}$ a finite value while the PCM is melting.

\subsubsection{Parameter estimates and solving method}

The parameters used in the detailed column model are summarized in Table 2. The other parameters related to the mass and heat transfer coefficients, $k, h_{\mathrm{BW}}, h_{\mathrm{WA}}$, and $U_{\mathrm{BPW}}$, were determined so that the calculated breakthrough curve and temperature distributions fit the experimental results. Based on the procedure reported by Marx et al., ${ }^{26}$ we first determined the mass transfer coefficient, $k$, and the heat transfer coefficients, $h_{\mathrm{BW}}$ and $h_{\mathrm{WA}}$, so that the simulated 
breakthrough curve and temperature in the column would coincide with the experimental data attained under condition A listed in Table 1 (see Supporting Information for more details). The experimental data under condition B, containing PCM pellets, were then used to determine the overall heat transfer coefficient, $U_{\mathrm{BPW}}$, where $k, h_{\mathrm{WA}}$, and $h_{\mathrm{BW}}$ were fixed at the values obtained from the fitting for condition A. Finally, we calculated the breakthrough behaviors and temperature distributions for conditions $\mathbf{C}-\mathbf{F}$ using the estimated parameters and compared the results with the experimental ones.

The partial differential equations derived from the material and energy balances were spatially discretized into 60 finite volumes with a constant length. The vanLeer method was applied as a flux limiter. ${ }^{32}$ Time integration was performed with the Sundials CVODE solver. ${ }^{33}$

Table 2 Parameters of the column model

\begin{tabular}{|c|c|c|c|}
\hline$L$ & Column length & 0.15 & $\mathrm{~m}$ \\
\hline$r_{\mathrm{i}}$ & Column inner radius & 0.005 & $\mathrm{~m}$ \\
\hline$r_{\mathrm{o}}$ & Column outer radius & 0.007 & $\mathrm{~m}$ \\
\hline$C_{\mathrm{p}, \mathrm{W}}$ & Heat capacity of column wall & $4.7 \times 10^{6}$ & $\mathrm{~J} \cdot \mathrm{m}^{-3} \cdot \mathrm{K}^{-1}$ \\
\hline$\lambda_{\mathrm{W}}$ & Axial thermal conductivity of column wall & 16.7 & $\mathrm{~J} \cdot \mathrm{m}^{-1} \cdot \mathrm{s}^{-1} \cdot \mathrm{K}^{-1}$ \\
\hline$\rho_{\mathrm{P}, \mathrm{AC}}$ & Particle density of activated carbon & 927.7 & $\mathrm{~kg}-\mathrm{AC} \cdot \mathrm{m}^{-3}$ \\
\hline$\rho_{\mathrm{M}, \mathrm{AC}}$ & Material density of activated carbon & 1930 & $\mathrm{~kg}-\mathrm{AC} \cdot \mathrm{m}^{-3}$ \\
\hline$\rho_{\mathrm{P}, \mathrm{PCM}}$ & Particle density of PCM & 880 & $\mathrm{~kg}-\mathrm{AC} \cdot \mathrm{m}^{-3}$ \\
\hline$C_{\mathrm{p}, \mathrm{AC}}$ & Heat capacity of activated carbon & 1000 & $\mathrm{~J} \cdot \mathrm{K}^{-1} \cdot \mathrm{kg}-\mathrm{AC}^{-1}$ \\
\hline$C_{\mathrm{p}, \mathrm{PW}}^{\mathrm{l}}$ & $\begin{array}{l}\text { Heat capacity of paraffin wax in liquid } \\
\text { phase }\end{array}$ & 2100 & $\mathrm{~J} \cdot \mathrm{K}^{-1} \cdot \mathrm{kg}-\mathrm{PW}^{-1}$ \\
\hline$C_{\mathrm{p}, \mathrm{PW}}^{\mathrm{s}}$ & Heat capacity of paraffin wax in solid phase & 1800 & $\mathrm{~J} \cdot \mathrm{K}^{-1} \cdot \mathrm{kg}-\mathrm{PW}^{-1}$ \\
\hline
\end{tabular}




\begin{tabular}{clll}
\hline$C_{\mathrm{p}, \mathrm{PR}}$ & Heat capacity of phenolic resin & 1665 & $\mathrm{~J} \cdot \mathrm{K}^{-1} \cdot \mathrm{kg}^{\mathrm{P}} \mathrm{PR}^{-1}$ \\
$\theta_{\mathrm{PW}}$ & Weight fraction of paraffin wax in PCM & 0.72 & $\mathrm{~kg}-\mathrm{PW} \cdot \mathrm{kg}-\mathrm{PCM}^{-1}$ \\
$\Delta H_{\mathrm{PW}}$ & Latent heat of paraffin wax & $247 \times 10^{3}$ & $\mathrm{~J} \cdot \mathrm{kg}-\mathrm{PW}^{-1}$ \\
$T_{\mathrm{m}}$ & Melting temperature of paraffin wax & 305 & $\mathrm{~K}$ \\
$\Delta T_{\mathrm{m}}$ & Melting temperature range of paraffin wax & 0.5 & $\mathrm{~K}$ \\
$C_{\mathrm{p}, \mathrm{N}_{2}}$ & Heat capacity of $\mathrm{N}_{2}$ & 29.2 & $\mathrm{~J} \cdot \mathrm{mol}^{-1} \cdot \mathrm{K}^{-1}$ \\
$C_{\mathrm{p}, n-\mathrm{butane}}$ & Heat capacity of $n$-butane & 98.8 & $\mathrm{~J} \cdot \mathrm{mol}^{-1} \cdot \mathrm{K}^{-1}$ \\
$D_{\mathrm{m}}$ & Molecular diffusion coefficient & $9.5 \times 10^{-5}$ & $\mathrm{~m}^{2} \cdot \mathrm{s}^{-1}$ \\
$\lambda_{\mathrm{B}}$ & Axial thermal conductivity of packed bed & 0.3 & $\mathrm{~J} \cdot \mathrm{m}^{-1} \cdot \mathrm{s}^{-1} \cdot \mathrm{K}^{-1}$ \\
\hline
\end{tabular}

\subsection{Evaluation of PCM in adiabatic adsorption process}

To investigate the thermal management properties of PCM on an adsorption process, the adsorption process under adiabatic conditions was simulated using the developed column model. In the calculation, we assumed a column with a length of $2.0 \mathrm{~m}$ and inner radius of $0.6 \mathrm{~m}$ under adiabatic conditions $\left(h_{\mathrm{BW}}=h_{\mathrm{WA}}=0\right)$. The total bed density of activated carbon and PCM, $\rho_{\mathrm{B}}$, was set to $450 \mathrm{~kg}-(\mathrm{AC} \& \mathrm{PCM}) \cdot \mathrm{m}^{-3}$. The flow rate and the $n$-butane mole fraction of feed gas were set to $1200 \mathrm{~m}^{3} \cdot \mathrm{h}^{-1}$ and 0.1 , respectively. The initial temperature of the column and gas stream temperature were $298 \mathrm{~K}$. We evaluated the amount adsorbed with various weight fractions for the $\mathrm{PCM}, \phi_{\mathrm{PCM}}$, and differing melting temperatures for the paraffin wax, $T_{\mathrm{m}}$, when the $n$-butane breaks through the column. The breakthrough was defined as the timing when the mole fraction of $n$ butane at the outlet reached 0.005 , which corresponds to $5 \%$ of that of the inlet.

\section{RESULTS AND DISCUSSION}

\subsection{Adsorption isotherm and Sips model}


Figure 3 shows the adsorption isotherms of $n$-butane and $\mathrm{N}_{2}$ on activated carbon at 283, 298, and $313 \mathrm{~K}$. The amount of adsorbed $n$-butane decreased as the temperature increased, which suggests performance degradation under adiabatic conditions. The amount of adsorbed $\mathrm{N}_{2}$ was almost zero at any measured temperature and pressure. Following the ideal adsorbed solution theory, ${ }^{34}$ the adsorption isotherm of a binary $n$-butane $/ \mathrm{N}_{2}$ mixture was then evaluated (Figure S3), which indicated that $\mathrm{N}_{2}$ adsorption from the gas mixture was negligible. Hence, we regarded $\mathrm{N}_{2}$ as an inert gas in the following discussion. The solid lines in Figure 3a show the Sips equation fitted to the experimental results, the parameters of which are listed in Table 3. The Sips equation accurately described the temperature dependence of the adsorption isotherm, so we used this equation and its parameter $Q$ in the detailed column model to calculate the equilibrium capacity and isosteric heat of adsorption. 

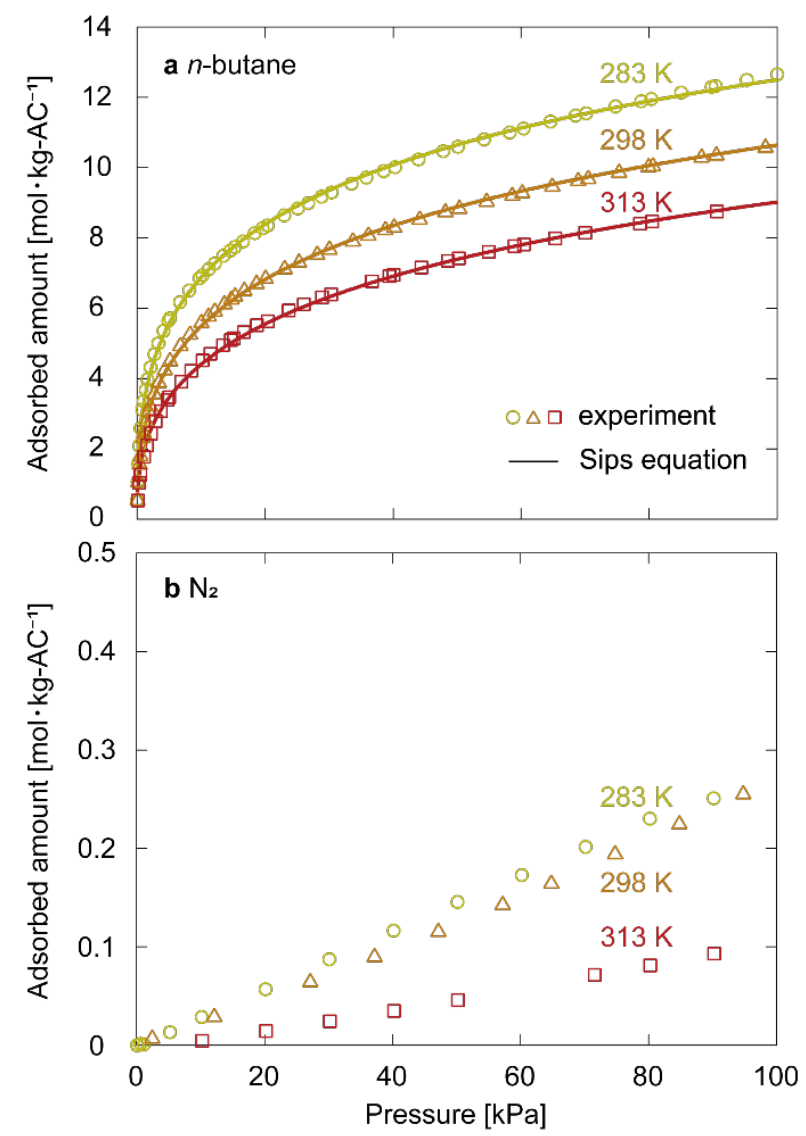

Figure 3 Single-component adsorption isotherms of (a) $n$-butane and (b) $\mathrm{N}_{2}$ on activated carbon at 283, 298, and $313 \mathrm{~K}$.

Table 3 Parameters of the Sips equation for $n$-butane adsorption on activated carbon

\begin{tabular}{lll}
\hline$n_{\mathrm{s} 0}$ & {$\left[\mathrm{~mol} \cdot \mathrm{kg}-\mathrm{AC}^{-1}\right]$} & 27.8 \\
$b_{0}$ & {$\left[\mathrm{~Pa}^{-1}\right]$} & $3.06 \times 10^{-6}$ \\
$s_{0}$ & {$[-]$} & 2.49 \\
$\chi$ & {$[-]$} & $7.4 \times 10^{-4}$ \\
$Q$ & {$\left[\mathrm{~kJ} \cdot \mathrm{mol}^{-1}\right]$} & 31.7
\end{tabular}




$\begin{array}{ccc}\alpha & {[-]} & 0.11 \\ T_{\text {ref }} & {[\mathrm{K}]} & 298\end{array}$

\subsection{Breakthrough curve measurements and parameter estimates}

Figures $4 \mathrm{a}$ and $4 \mathrm{~b}$ show the breakthrough curve and temperatures in the column measured under condition A. In this condition, without PCM pellets, the breakthrough occurred at $1060 \mathrm{~s}$, and the temperature of the column increased by approximately $22 \mathrm{~K}$. However, while the breakthrough time in condition $\mathbf{B}$, containing PCM pellets, was shorter than that in condition $\mathbf{A}$, the temperature increase was only $16 \mathrm{~K}$, as shown in Figures $4 \mathrm{c}$ and $4 \mathrm{~d}$. It was $27 \%$ smaller than in condition $\mathbf{A}$. These results indicate that PCM pellets absorbed the heat of adsorption and suppressed the temperature increases of the column. However, the net adsorption capacity of the column was not improved because the negative effect of the TES system, which reduces the adsorbent content, was dominant in these experiments.

By using these data, we estimated parameters associated with the mass and heat transfer, as shown in Table 4. The solid lines in Figure 4 show the breakthrough curve and temperatures obtained from the detailed column model, and they were in good agreement with the experimental results. A slight difference between the experimental and calculated results might be caused by the simplification assuming the temperatures of the gas phase, adsorbent, and phenolic resin of the PCM as uniform; however, the prediction accuracy of our model should be sufficient for engineering use. Four additional breakthrough experiments listed in Table 1 were conducted to confirm the validity of the estimated parameters, and these results are shown in Figure S4. Here, conditions $\mathbf{C}$ and $\mathbf{D}$ are different from condition $\mathbf{A}$ in the $n$-butane fraction and flow rate of feed, and conditions $\mathbf{E}$ and $\mathbf{F}$ are those for condition $\mathbf{B}$. Reducing the $n$-butane fraction of the feed 
(conditions $\mathbf{C}$ and $\mathbf{E}$ ) resulted in longer breakthrough times and smaller temperature increases than conditions $\mathbf{A}$ and $\mathbf{B}$. In contrast, increasing the flow rate (conditions $\mathbf{D}$ and $\mathbf{F}$ ) shortened the breakthrough time and enlarged the temperature increases. Although these conditions differ significantly from each other in terms of the $n$-butane fraction of feed, flow rate, and weight fraction of PCM, the calculated breakthrough curves and temperatures using the developed column model were in good agreement with the experimental results. This result indicates that our detailed column model can accurately simulate the adsorption behavior of the PCM integrated column.
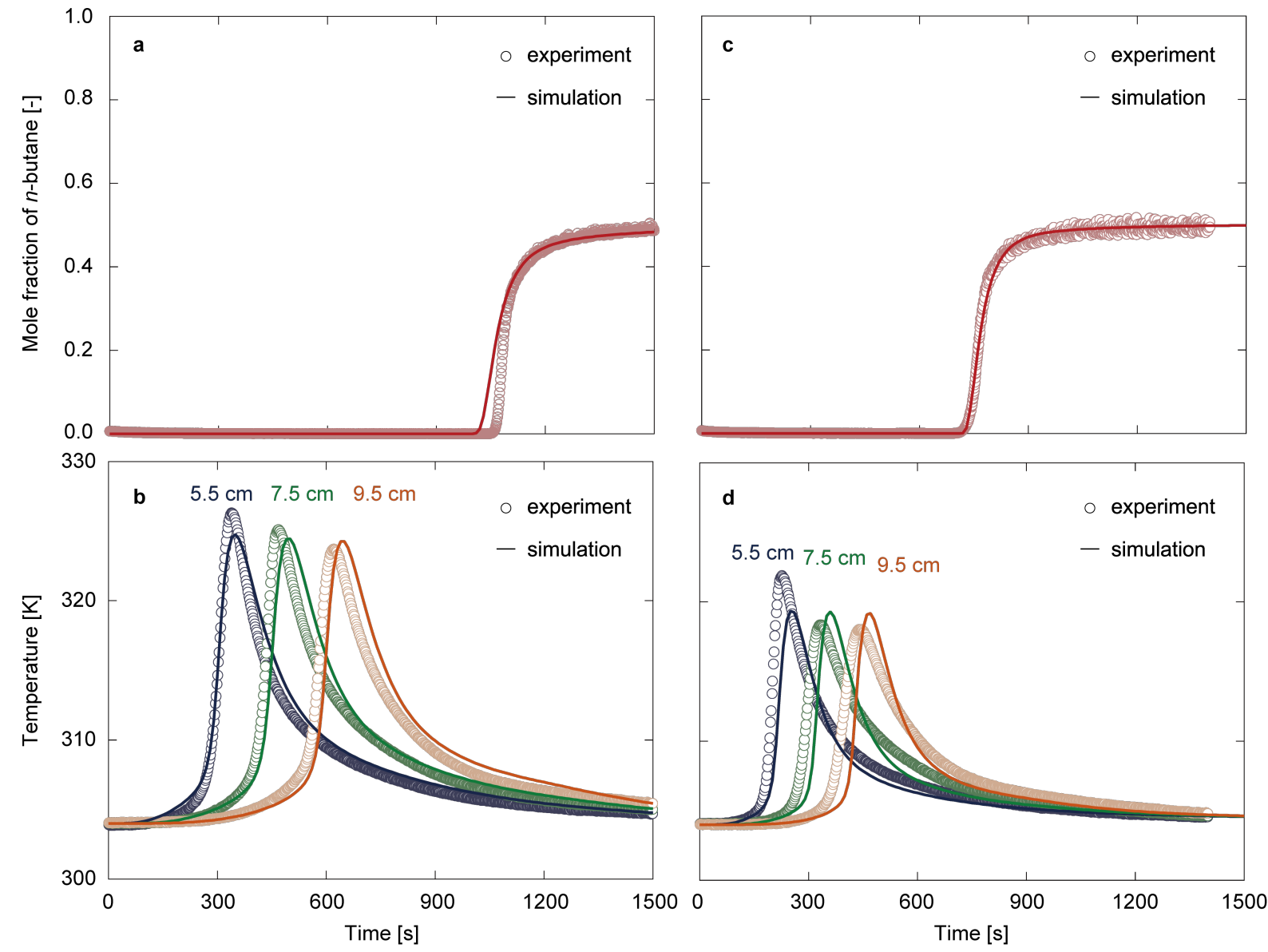

Figure 4 (a) Breakthrough curve and (b) bed temperatures measured 5.5, 7.5, and $9.5 \mathrm{~cm}$ from the column inlet under condition A. (c) and (d) are those under condition B. Symbols represent experimental data, and solid lines are those calculated using the column model. 
Table 4 Estimated mass and heat transfer coefficients

\begin{tabular}{lll}
\hline$k$ & {$\left[\mathrm{~s}^{-1}\right]$} & 0.046 \\
$h_{\mathrm{BW}}$ & {$\left[\mathrm{J} \cdot \mathrm{m}^{-2} \cdot \mathrm{s}^{-1} \cdot \mathrm{K}^{-1}\right]$} & 80 \\
$h_{\mathrm{WA}}$ & {$\left[\mathrm{J} \cdot \mathrm{m}^{-2} \cdot \mathrm{s}^{-1} \cdot \mathrm{K}^{-1}\right]$} & 34 \\
$U_{\mathrm{BPW}}$ & {$\left[\mathrm{J} \cdot \mathrm{kg}-\mathrm{PCM}^{-1} \cdot \mathrm{s}^{-1} \cdot \mathrm{K}^{-1}\right]$} & 60 \\
\hline
\end{tabular}

\subsection{Evaluation of PCM in adiabatic adsorption process}

Using the developed column model, we simulated $n$-butane adsorption in the adiabatic column and varied the $\phi_{\mathrm{PCM}}$ and $T_{\mathrm{m}}$. As a typical example, we first discussed the effects of $\phi_{\mathrm{PCM}}$ when $T_{\mathrm{m}}=313$ $\mathrm{K}$. When the $\phi_{\mathrm{PCM}}=0$, a breakthrough curve occurred at $0.42 \mathrm{~h}$ (Figure 5a). The temperatures at $1 / 4,1 / 2$, and $3 / 4$ of the column height were also observed under this condition (Figure $5 b$ ). The bed temperature at each point increased rapidly to $385 \mathrm{~K}$, due to the heat of adsorption, and remained constant for a certain time. This plateau was caused by the difference between the rate of adsorption and the cooling rate by the inlet flow, which is evident in the temperature distribution inside the column (Figure 6a). Due to the heat of adsorption, the temperature of the column increased according to the movement of the mass transfer zone. On the other hand, the adiabatic column could only be cooled by the inlet flow at $298 \mathrm{~K}$, because the heat transfer between the column and ambience is limited. This results in gradual cooling from the entrance; that is, the temperature at the plateau $(385 \mathrm{~K})$ corresponds to the temperature reached by adiabatic adsorption without convective heat transfer by the gas stream. The temperature distribution of the column at the breakthrough (blue line in Figure 6a) indicates that the adsorption performance of the column 
can be approximated by the equilibrium loading at the plateau temperature $(385 \mathrm{~K})$. The adsorbent at the plateau temperature was gradually cooled to $298 \mathrm{~K}$ by the inlet gas. At this time, additional adsorption occurred because the adsorbent had been saturated at $385 \mathrm{~K}$, but not at $298 \mathrm{~K}$. This phenomenon is reflected in the breakthrough curve (Figure 5a), where the mole fraction of $n$ butane gradually increased from 0.055 to the value of the feed gas (0.1) after the breakthrough. This increase demonstrates how much the heat of adsorption reduced the adsorption capacity of the adsorbent. In fact, when $\phi_{\mathrm{PCM}}=0.3$, the mole fraction of $n$-butane directly after the breakthrough was 0.089 (Figure 5c). This is owing to the latent heat of PCM that absorbed the heat of adsorption and maintained a low column temperature (Figure 5d). However, the profile is slightly complicated: $T_{1}$ represents an overshoot due to the adsorption being faster than the heat transfer between the bed and paraffin wax (Figure 6b); $T_{2}$ corresponds to the plateau temperature in Figure 5b, but it is determined by the heat balance between the heat of adsorption, sensible heat of the bed, and latent heat of PCM; and $T_{3}$ is the temperature at which the molten paraffin wax refreezes. Although placing PCM in the column reduced the adsorbent content, the breakthrough time when $\phi_{\mathrm{PCM}}=0.3(0.47 \mathrm{~h})$ was longer than when $\phi_{\mathrm{PCM}}=0(0.42 \mathrm{~h})$. 

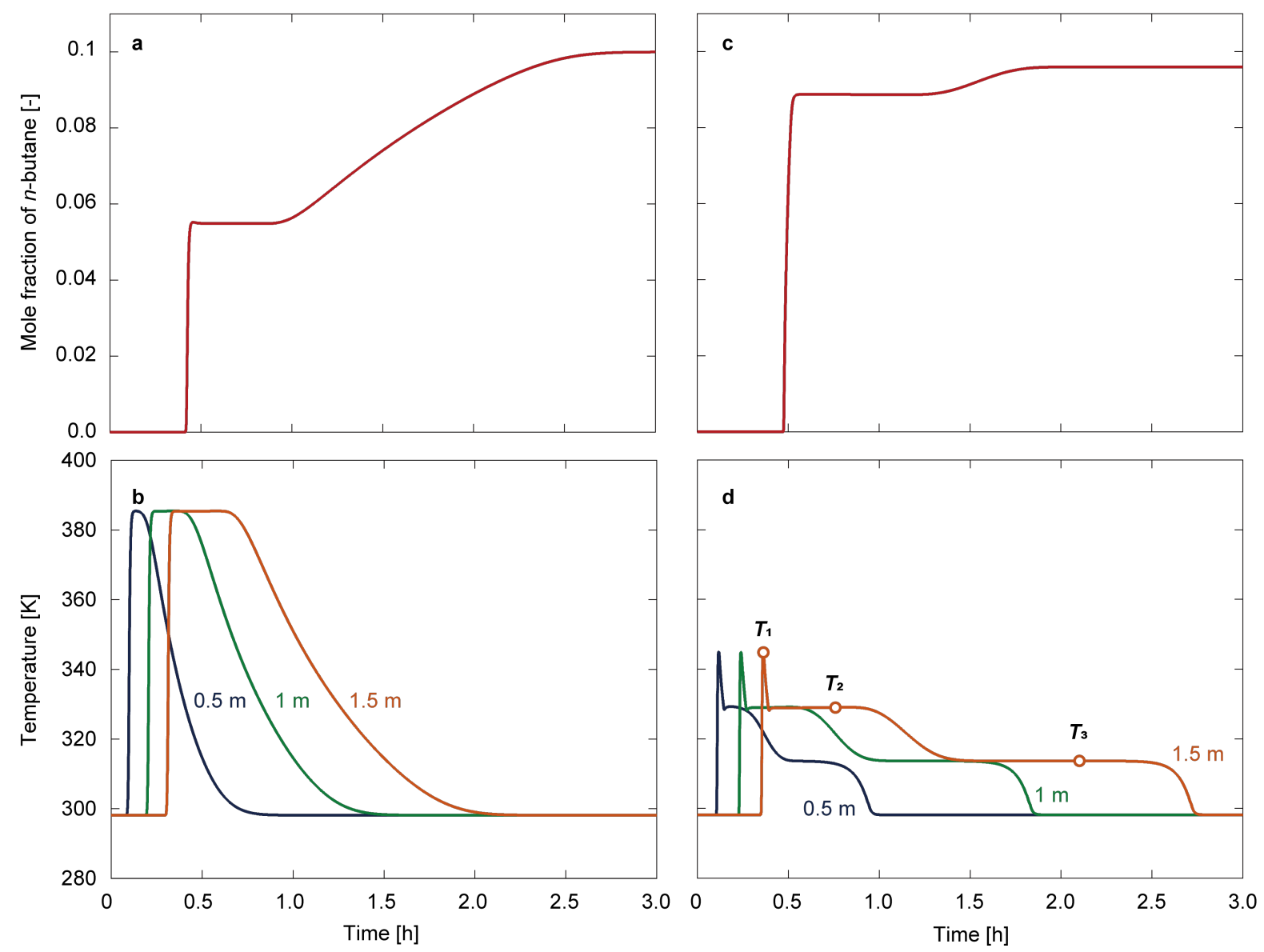

Figure 5 (a) Breakthrough curve and (b) bed temperatures of the adiabatic column containing no $\operatorname{PCM}\left(\phi_{\mathrm{PCM}}=0\right)$ calculated using the developed column model. $(\mathrm{c})$ and $(\mathrm{d})$ are those when $\phi_{\mathrm{PCM}}=$ 0.3 . 


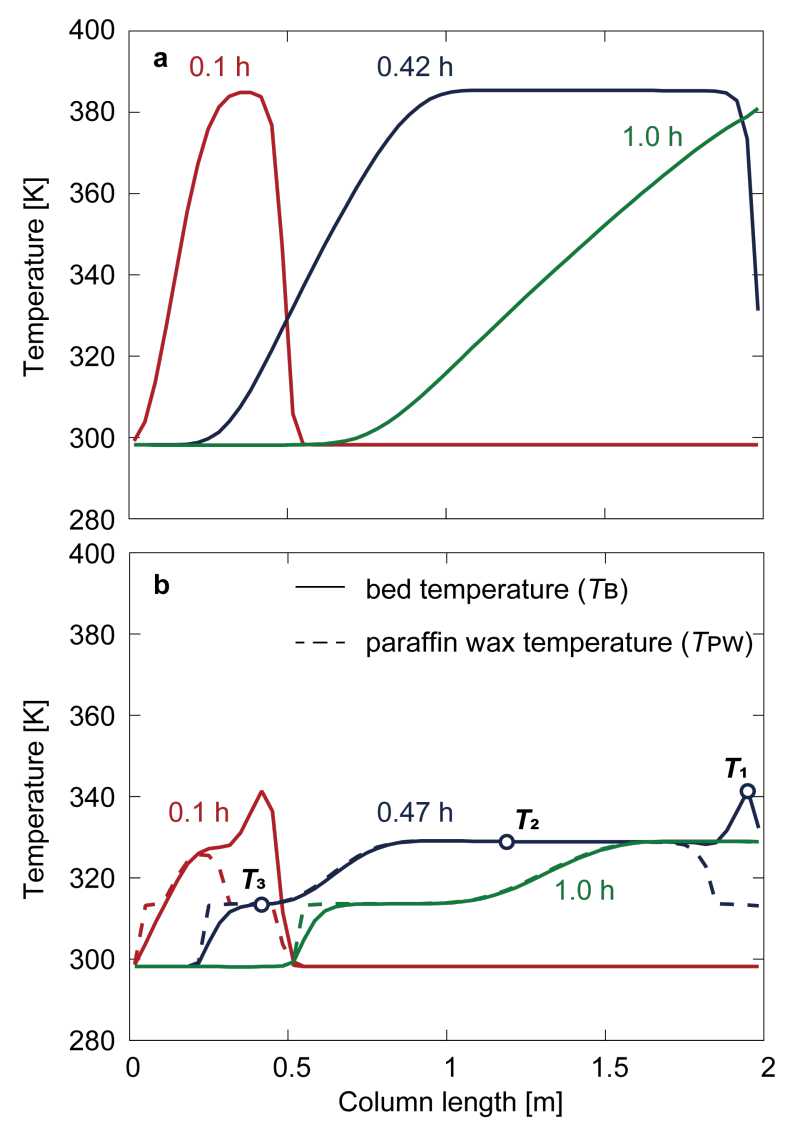

Figure 6 Temperature distributions in the column when (a) $\phi_{\mathrm{PCM}}=0$ and (b) $\phi_{\mathrm{PCM}}=0.3$. Bed (solid line) and paraffin wax (dotted line) temperatures after $0.1 \mathrm{~h}$ (red), breakthrough time (blue), and $1.0 \mathrm{~h}$ (green).

The $\phi_{\mathrm{PCM}}$ dependence on the amount of adsorbed $n$-butane, together with the peak-top temperature $\left(T_{1}\right.$ in Figure $\left.5 \mathrm{~d}\right)$ and plateau temperature $\left(T_{2}\right.$ in Figure $\left.5 \mathrm{~d}\right)$, could be observed when $n$-butane broke through the column (Figure 7a). Both $T_{1}$ and $T_{2}$ decreased monotonically with the $\phi_{\mathrm{PCM}}$ increasing to 0.4 , and the adsorbed amount increased as the temperature decreased. For example, the adsorbed amount when $\phi_{\mathrm{PCM}}=0.3$ was almost twice as large as when $\phi_{\mathrm{PCM}}=0$, which indicates that the adsorption performance can be dramatically improved by installing PCM. 
However, the improvement rate of the amount adsorbed was nearly saturated at $\phi_{\mathrm{PCM}}=0.4$. This is simply because an excessive amount of PCM was inserted compared to the net heat generated by adsorption. In fact, $T_{2}$, which occupied most of the column at the breakthrough (Figure 6b), was equal to the melting temperature $T_{\mathrm{m}}(313 \mathrm{~K})$ when $\phi_{\mathrm{PCM}}=0.4-0.8$. The slight increase in the adsorbed amount per weight of adsorbent when $\phi_{\mathrm{PCM}}=0.9$ stems from the plateau temperature being lower than the $T_{\mathrm{m}}$, where all the heat generated by adsorption is covered by the sensible heat of the adsorbent and PCM. Figure $7 \mathrm{~b}$ shows the relationship between $\phi_{\mathrm{PCM}}$ and the total amount of $n$-butane adsorbed in the entire column. Although placing PCM in the column reduces the adsorbent content that can be packed in it, the adsorbed amount of the column reached the maximum at $\phi_{\mathrm{PCM}}=0.3$. This means that, by including PCM, a $70 \%$ amount of adsorbent can exceed the performance of the column consisting of adsorbent alone. Furthermore, if we redesign the column when $\phi_{\mathrm{PCM}}=0.3$ so that it has the same throughput capacity as the column when $\phi_{\mathrm{PCM}}$ $=0$, the amount of adsorbent and the column length can be reduced by $38 \%$ and $11 \%$, respectively. These results show that thermal management using PCM is useful in the adsorption separation process. 

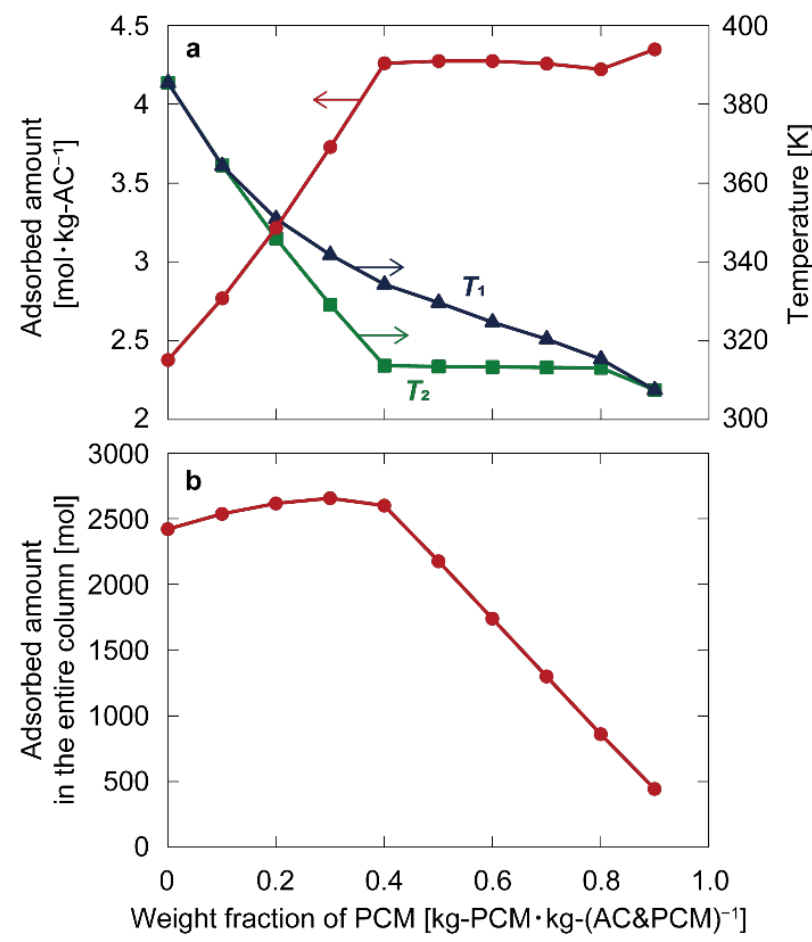

Figure 7 PCM dependence on $n$-butane adsorption. (a) The amount of $n$-butane adsorbed onto activated carbon at breakthrough (red circle); the peak-top temperature, $T_{1}$ (blue triangle); and the plateau temperature, $T_{2}$ (green square). (b) The entire adsorbed amount of $n$-butane at breakthrough.

Figure 8 replots Figure $7 \mathrm{~b}$ together with the results at various $T_{\mathrm{m}}$ values. Lowering $T_{\mathrm{m}}$ increased the adsorbed amount, and the maximum peak of the adsorbed amount was shifted to the lower $\phi_{\mathrm{PCM}}$ side by increasing $T_{\mathrm{m}}$. This is because the amount of heat absorbed by the phase transition of PCM depends on the temperature. This behavior can be predicted using a simple heat balance equation since the equilibrium loading at $T_{2}$ is dominant in determining the breakthrough behavior (blue line in Figure 6b). Figure 9a shows the integral heat of $n$-butane adsorption at 10 $\mathrm{kPa}$ (the partial pressure of the feed $n$-butane) and the enthalpy of the bed (the mixture of the adsorbent and PCM) by adsorbent weight. The blue, green, and orange lines represent the beds containing $30 \mathrm{wt} \%$ PCM pellets with the melting temperatures of 303, 323, and $343 \mathrm{~K}$, respectively. 
The integral heat of adsorption, derived by $n^{*}\left(T_{\mathrm{B}}\right) Q$, represents the heat generated when the adsorbed amount increases from 0 to $n^{*}\left(T_{\mathrm{B}}\right)$. The bed enthalpy, on the other hand, describes the pathway through which the bed absorbs the heat with its temperature increased. Neglecting the heat transfer via gas stream and the axial thermal conduction of the bed, all the heat generated by adsorption is consumed to increase the bed temperature. That is, the equilibrium loading and degree of temperature increase under the adiabatic conditions are determined such that the heat generated by adsorption is commensurate with the heat required to change the bed temperature. For example, the bed with $\phi_{\mathrm{PCM}}=0.3$ and $T_{\mathrm{m}}=303 \mathrm{~K}$ is initially in state $\mathbf{A}$ and absorbs the heat of adsorption to increase its temperature until $T_{\mathrm{m}}$ (state $\mathbf{B}$ ). Then, because paraffin wax melts at $T_{\mathrm{m}}$, the bed enthalpy increases by the retained amount of latent heat with the temperature (state $\mathbf{C}$ ). After melting, the bed temperature begins to increase again by absorbing the heat of adsorption as the sensible heat for adsorbents, phenolic resins, and liquid-phase paraffin wax. Finally, the bed enthalpy has intersection point $\mathbf{D}$ with the integral heat of adsorption. The temperature in state $\mathbf{D}$ is that which the bed reaches in the adiabatic adsorption process, and up to the equilibrium loading at this temperature, activated carbon can adsorb $n$-butane. Considering that the adsorbed amount at equilibrium increases with decreasing temperature, the adsorption performance of the column improves when the bed enthalpy intersects with the integral heat of adsorption at a lower temperature. Therefore, extending line $\mathbf{B C}$ and lowering the temperature in state $\mathbf{D}$ should be effective and can be attained by increasing $\phi_{\mathrm{PCM}}$. In contrast, the bed enthalpy with $T_{\mathrm{m}}=343 \mathrm{~K}$ intersects with the red line at point $\mathbf{G}$, which internally divides line $\mathbf{E F}$, representing the latent heat. This result indicates that the paraffin wax does not completely melt and that decreasing $\phi_{\mathrm{PCM}}$ to provide space for packing additional adsorbent improves the overall adsorption performance of the column. In that sense, the bed with $\phi_{\mathrm{PCM}}=0.3$ and $T_{\mathrm{m}}=323 \mathrm{~K}$ (the green line), wherein the 
latent heat is fully utilized without waste, is promising. More specifically, the optimum weight fraction of PCM, $\phi^{\mathrm{opt}}$, can be determined by the following procedure. First, consider the maximum temperature, $T^{\mathrm{max}}$, that the column without PCM reaches in the adiabatic process by solving the following energy balance equation:

$$
C_{\mathrm{p}, \mathrm{AC}}\left(T^{\max }-T_{\mathrm{ini}}\right)=n^{*}\left(T^{\max }\right) Q
$$

where $T_{\text {ini }}$ is the bed temperature before the adiabatic adsorption process and $n^{*}\left(T^{\max }\right)$ is the equilibrium loading at $T^{\mathrm{max}}$ obtained from Equation (17). If a given $T_{\mathrm{m}}$ is smaller than $T_{\mathrm{ini}}$ or larger than $T^{\text {max }}$, integrating PCM does not make sense (it has meaning as sensible heat type TES, but in that case, there is no point in using PCM). When $T_{\mathrm{ini}} \leq T_{\mathrm{m}}<T^{\max }$ is satisfied, calculate the upper limit of the weight fraction of PCM, $\phi^{u l}$, which can decrease the temperature reached by the column during the adiabatic process. As clearly shown in Figure 9a, the temperature reached by the bed with $T_{\mathrm{m}}=343 \mathrm{~K}$ does not change from $T_{\mathrm{m}}$ even if $\phi_{\mathrm{PCM}}$ is increased further. That is, $\phi^{\mathrm{ul}}$ is the weight fraction that superposes point $\mathbf{G}$ on point $\mathbf{F}$, and it is obtained by:

$$
\phi^{\mathrm{ul}}=\frac{n^{*}\left(T_{\mathrm{m}}\right) Q-C_{\mathrm{p}, \mathrm{AC}}\left(T_{\mathrm{m}}-T_{\mathrm{ref}}\right)}{n^{*}\left(T_{\mathrm{m}}\right) Q+\Delta H_{\mathrm{PW}} \theta_{\mathrm{PW}}+\left[C_{\mathrm{p}, \mathrm{PW}}^{\mathrm{s}} \theta_{\mathrm{PW}}+C_{\mathrm{p}, \mathrm{PR}}\left(1-\theta_{\mathrm{PW}}\right)-C_{\mathrm{p}, \mathrm{AC}}\right]\left(T_{\mathrm{m}}-T_{\mathrm{ref}}\right)} .
$$

The optimum weight fraction of PCM maximizes the entire adsorbed amount of the column, $N$ :

$$
N=\pi r_{\mathrm{i}}^{2} L \rho_{\mathrm{B}}\left(1-\phi_{\mathrm{PCM}}\right) n^{*}\left(T^{\mathrm{ad}}\right)
$$

in the range of $0 \leq \phi_{\mathrm{PCM}} \leq \phi^{\text {ul }}$. Within this range, the adiabatic column temperature, $T^{\mathrm{ad}}$, which corresponds to $T_{2}$ in Figure 5 d, is determined by the following equation:

$$
\begin{gathered}
{\left[C_{\mathrm{p}, \mathrm{AC}}\left(1-\phi_{\mathrm{PCM}}\right)+C_{\mathrm{p}, \mathrm{PR}} \phi_{\mathrm{PCM}}\left(1-\theta_{\mathrm{PW}}\right)\right]\left(T^{\mathrm{ad}}-T_{\mathrm{ref}}\right)+} \\
\phi_{\mathrm{PCM}} \theta_{\mathrm{PW}}\left[C_{\mathrm{p}, \mathrm{PW}}^{\mathrm{s}}\left(T_{\mathrm{m}}-T_{\mathrm{ref}}\right)+C_{\mathrm{p}, \mathrm{PW}}^{\mathrm{l}}\left(T^{\mathrm{ad}}-T_{\mathrm{m}}\right)\right]+\Delta H_{\mathrm{PW}} \phi_{\mathrm{PCM}} \theta_{\mathrm{PW}}= \\
\left(1-\phi_{\mathrm{PCM}}\right) n^{*}\left(T^{\mathrm{ad}}\right) Q .
\end{gathered}
$$


Figure $9 \mathrm{~b}$ shows the bed enthalpy curves when $\phi_{\mathrm{PCM}}=\phi^{\mathrm{opt}}$ is estimated by numerically solving Equations (25) and (26). In all conditions, the intersection of the bed enthalpy and integral heat of adsorption matches the endpoint of the latent heat, which means that the calculated $\phi^{\mathrm{ppt}}$ is equal to $\phi^{\text {al }}$. This result can be qualitatively explained by the derivative of $N$ :

$$
\frac{\mathrm{d} N}{\mathrm{~d} \phi_{\mathrm{PCM}}}=\pi r_{\mathrm{i}}^{2} L \rho_{\mathrm{B}} n^{*}\left(T^{\mathrm{ad}}\right)\left[\left(1-\phi_{\mathrm{PCM}}\right) \frac{\frac{\mathrm{d} n^{*} \mathrm{~d} T^{\mathrm{ad}}}{\mathrm{d} T^{\mathrm{add} \phi_{\mathrm{PCM}}}}}{n^{*}\left(T^{\mathrm{ad}}\right)}-1\right] .
$$

The first term in parentheses on the right side expresses the relative increase in the adsorbed amount with respect to the change in $\phi_{\mathrm{PCM}}$. Unless the bed temperature is quite low and/or the gas pressure is quite high, the relative increase in the adsorbed amount as the temperature decreases should be large. This fact results in $\mathrm{d} N / \mathrm{d} \phi_{\mathrm{PCM}}>0$; thus, $N$ takes the maximum at $\phi_{\mathrm{PCM}}=\phi^{\text {ul }}$. In other words, the optimum weight fraction of PCM can be evaluated from Equation (24) in most cases. The dashed line in Figure 8 shows the estimated $\phi^{\text {opt }}$ for each melting temperature and is in good agreement with the maximum peak of the result simulated by using the detailed column model. These results demonstrate that the $\phi^{\text {ppt }}$ for a given melting temperature can be predicted without complicated calculations using a detailed column model, which should be useful information for industrial applications. 


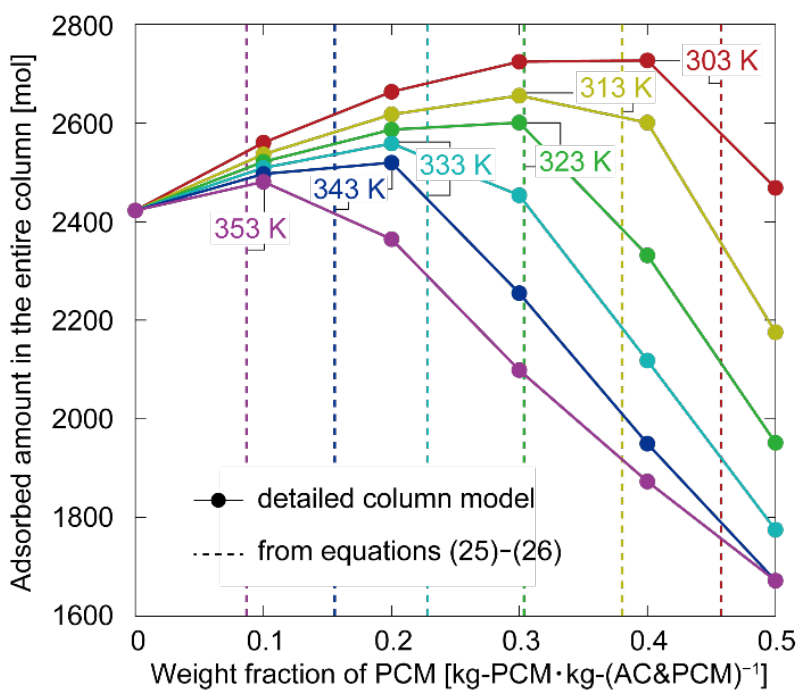

Figure 8 The total adsorbed amount of the column at various melting temperatures $(303 \mathrm{~K}-353$ K). Dashed lines are the optimum weight fraction of PCM obtained from Equations (25)-(26).

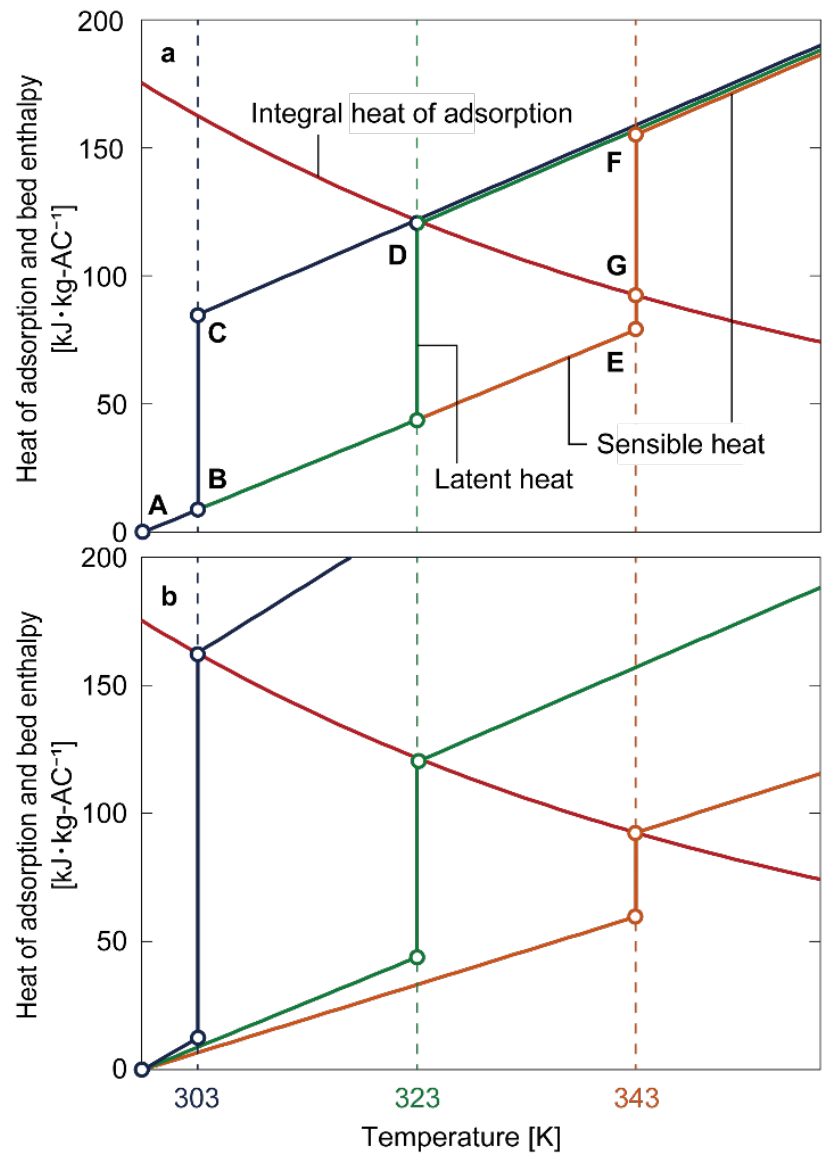


Figure 9 Schematic diagram for the simple heat balance equation consisting of integral heat of adsorption (red line) and bed enthalpy: (a) $\phi_{\mathrm{PCM}}=0.3$ and (b) $\phi_{\mathrm{PCM}}=\phi^{\mathrm{ppt}}$. Blue, green, and orange lines represent the beds with $T_{\mathrm{m}}=303,323$, and $343 \mathrm{~K}$, respectively.

\section{CONCLUSIONS}

We measured breakthrough curves for adsorption columns containing activated carbon and PCM pellets and found that introducing the PCM suppressed the temperature increase inside the column. We then developed a one-dimensional nonisothermal column model considering the melting effect of PCM. The parameters related to the mass and heat transfer of the column model were estimated by fitting the calculated breakthrough curves and bed temperatures to the experiment data under two conditions. Four more experiments and calculations confirmed that our detailed column model successfully reproduced the adsorption behavior in the column containing PCM.

By using the developed column model, an adiabatic adsorption process containing PCM was simulated to investigate the influence of the properties of PCM on the adsorption performance. While integrating PCM into the adsorption column reduces the amount of adsorbent to be packed, it was possible to increase the adsorption capacity not only per the amount of adsorbent but also per the volume of the column by mixing an adequate amount of PCM in. It was also found that the optimum weight fraction of PCM that maximizes the adsorption capacity of the column depends on the melting temperature of paraffin wax. A simple heat balance equation consisting of the heat of adsorption and the bed enthalpy clarified the melting temperature dependence of the optimum weight fraction of PCM and succeeded in predicting it. This equation would help determine the optimum weight fraction of PCM for a given temperature in industrial applications. 
Future investigations aim to elucidate the function of PCM under the cyclic steady state of the entire PSA process, including the adsorption, purging, desorption, and rinsing steps. Furthermore, the melting temperature would play a crucial role because it controls the timing when the latent heat is given. Such a study is now in progress.

\section{ASSOCIATED CONTENT}

\section{Supporting Information}

The Supporting Information is available free of charge on the ACS Publications website.

Differential scanning calorimetry curve of PCM; adsorption isotherms on activated carbon and PCM; adsorption isotherm of a $n$-butane/ $\mathrm{N}_{2}$ gas mixture on activated carbon evaluated by IAST; experimental and calculated breakthrough curves and temperatures for four conditions $(\mathbf{C}-\mathbf{F})$; the parameter estimates procedure $(\mathrm{PDF})$

\section{AUTHOR INFORMATION}

\section{Corresponding Authors}

*E-mail: hiraide@cheme.kyoto-u.ac.jp

*E-mail: miyahara@cheme.kyoto-u.ac.jp

\section{Notes}

The authors declare no competing financial interest.

\section{ACKNOWLEDGMENT}


This work was financially supported by a Grant-in-Aid for Challenging Research (Exploratory) no. 18K18975, a Grant-in-Aid for Research Activity Start-up no. 19K23574 and a Grant-in-Aid for Early-Career Scientists no. 20K15074. S.H. and Y.S. thank Dr. Yuta Hikima and Ms. Jisuk Lee for help in measuring differential scanning calorimetry curves.

\section{NOTATION}

\begin{tabular}{|c|c|c|}
\hline$a_{\mathrm{W}}$ & cross-sectional area of column & {$\left[\mathrm{m}^{2}\right]$} \\
\hline$b_{i}$ & affinity constant & {$\left[\mathrm{Pa}^{-1}\right]$} \\
\hline$b_{\mathrm{ref}, i}$ & reference values of $b_{i}$ at $T_{\text {ref }}$ & {$\left[\mathrm{Pa}^{-1}\right]$} \\
\hline$C_{\mathrm{p}, \mathrm{AC}}$ & heat capacity of activated carbon & {$\left[\mathrm{J} \cdot \mathrm{K}^{-1} \cdot \mathrm{kg}-\mathrm{AC}^{-1}\right]$} \\
\hline$C_{\mathrm{p}, i}$ & heat capacity of gas species $i$ & {$\left[\mathrm{~J} \cdot \mathrm{mol}^{-1} \cdot \mathrm{kg}^{-1}\right]$} \\
\hline$C_{\mathrm{p}, \mathrm{PW}}^{\mathrm{l}}$ & heat capacity of paraffin wax in liquid phase & {$\left[\mathrm{J} \cdot \mathrm{K}^{-1} \cdot \mathrm{kg}-\mathrm{PW}^{-1}\right]$} \\
\hline$C_{\mathrm{p}, \mathrm{PW}}^{\mathrm{s}}$ & heat capacity of paraffin wax in solid phase & {$\left[\mathrm{J} \cdot \mathrm{K}^{-1} \cdot \mathrm{kg}-\mathrm{PW} \mathbf{W}^{-1}\right]$} \\
\hline$C_{\mathrm{p}, \mathrm{PR}}$ & heat capacity of phenolic resin & {$\left[\mathrm{J} \cdot \mathrm{K}^{-1} \cdot \mathrm{kg}-\mathrm{PR}^{-1}\right]$} \\
\hline$C_{\mathrm{p}, \mathrm{W}}$ & heat capacity of column wall & {$\left[\mathrm{J} \cdot \mathrm{K}^{-1} \cdot \mathrm{kg}^{-1}\right]$} \\
\hline$c$ & total concentration of gas phase & {$\left[\mathrm{mol} \cdot \mathrm{m}^{-3}\right]$} \\
\hline$c_{i}$ & gas phase concentration of species $i$ & {$\left[\mathrm{~mol} \cdot \mathrm{m}^{-3}\right]$} \\
\hline$c_{i}^{\mathrm{feed}}$ & feed gas phase concentration of species $i$ & {$\left[\mathrm{~mol} \cdot \mathrm{m}^{-3}\right]$} \\
\hline$D_{\mathrm{L}}$ & axial dispersion coefficient & {$\left[\mathrm{m}^{2} \cdot \mathrm{s}^{-1}\right]$} \\
\hline$D_{\mathrm{m}}$ & molecular diffusion coefficient & {$\left[\mathrm{m}^{2} \cdot \mathrm{s}^{-1}\right]$} \\
\hline
\end{tabular}


$d_{\mathrm{p}} \quad$ Sauter mean diameter $\quad[\mathrm{m}]$

$\Delta H_{\mathrm{ads}, i}$ isosteric heat of adsorption $\quad\left[\mathrm{J} \cdot \mathrm{mol}^{-1}\right]$

$H_{i} \quad$ enthalpy of gas phase of species $i \quad\left[\mathrm{~J} \cdot \mathrm{mol}^{-1}\right.$ ]

$H_{i}^{\text {feed }}$ enthalpy of feed gas phase of species $i \quad\left[\mathrm{~J} \cdot \mathrm{mol}^{-1}\right]$

$H_{\mathrm{PW}} \quad$ enthalpy of paraffin wax $\quad\left[\mathrm{J} \cdot \mathrm{kg}-\mathrm{PW}^{-1}\right]$

$H_{\text {ref,Pw }}$ enthalpy of paraffin wax at $T_{\text {ref }} \quad\left[\mathrm{J} \cdot \mathrm{kg}-\mathrm{PW}^{-1}\right]$

$\Delta H_{\mathrm{PW}} \quad$ latent heat of paraffin wax $\quad\left[\mathrm{J} \cdot \mathrm{kg}^{\mathrm{P}} \mathrm{PW}{ }^{-1}\right]$

$h_{\mathrm{BW}}$ heat transfer coefficient between packed bed and column $\left[\mathrm{J} \cdot \mathrm{m}^{-2} \cdot \mathrm{s}^{-1} \cdot \mathrm{K}^{-1}\right]$ wall

$h_{\mathrm{WA}}$ heat transfer coefficient between column wall and $\left[\mathrm{J} \cdot \mathrm{m}^{-2} \cdot \mathrm{s}^{-1} \cdot \mathrm{K}^{-1}\right]$ environment

$J_{i} \quad$ mole flux of species $i \quad\left[\mathrm{~mol} \cdot \mathrm{m}^{-2} \cdot \mathrm{s}^{-1}\right]$

$k_{i} \quad$ adsorption rate constant $\quad\left[\mathrm{s}^{-1}\right]$

L column length $\quad[\mathrm{m}]$

$N$ entire adsorbed amount of column $\quad[\mathrm{mol}]$

$n_{i} \quad$ amount of adsorbed $i \quad\left[\mathrm{~mol} \cdot \mathrm{kg}-\mathrm{AC}^{-1}\right]$

$n_{i}^{*} \quad$ equilibrium loading of species $i \quad\left[\mathrm{~mol} \cdot \mathrm{kg}-\mathrm{AC}^{-1}\right]$

$n_{\mathrm{sref}, i} \quad$ reference values of $n_{\mathrm{s}, i}$ at $T_{\mathrm{ref}} \quad\left[\mathrm{mol} \cdot \mathrm{kg}-\mathrm{AC}^{-1}\right]$

$n_{\mathrm{s}, i} \quad$ saturation capacity of species $i \quad\left[\mathrm{~mol} \cdot \mathrm{kg}-\mathrm{AC}^{-1}\right]$

$p$ pressure $\quad[\mathrm{Pa}]$

$Q_{i} \quad$ isosteric heat when fractional loading is $0.5 \quad\left[\mathrm{~J} \cdot \mathrm{mol}^{-1}\right]$

$R$ gas constant $\quad\left[\mathrm{J} \cdot \mathrm{mol}^{-1} \cdot \mathrm{K}^{-1}\right]$

$r_{\mathrm{i}}$ inner radius of column [m]

$r_{\mathrm{O}}$ outer radius of column [m]

$s_{i} \quad$ Sips constant characterizing heterogeneity of adsorbent [-] surface

$S_{\text {ref, } i} \quad$ reference values of $s_{i}$ at $T_{\text {ref }} \quad[-]$ 
$T_{\mathrm{A}}$ ambient temperature

[K]

$T^{\text {ad }} \quad$ estimated bed temperature in adiabatic adsorption process

$T_{\mathrm{B}} \quad$ bed temperature

$T_{\text {ini } \quad \text { initial temperature }}$

$T_{\mathrm{m}} \quad$ melting temperature of paraffin wax

$\Delta T_{\mathrm{m}} \quad$ melting temperature range of paraffin wax

$T^{\max } \quad$ maximum temperature

$T_{\text {ref }} \quad$ reference temperature

$T_{\mathrm{PW}} \quad$ temperature of paraffin wax

$T_{\mathrm{W}} \quad$ temperature of column wall

$t$ time

[s]

$U_{\mathrm{BPW}}$ overall heat transfer coefficient between packed bed and

$\left[\mathrm{J} \cdot \mathrm{kg}-\mathrm{PCM}^{-1} \cdot \mathrm{s}^{-1} \cdot \mathrm{K}^{-1}\right]$ paraffin wax

$u \quad$ superficial gas velocity

$\left[\mathrm{m} \cdot \mathrm{s}^{-1}\right]$

$u^{\text {feed }} \quad$ superficial gas velocity of feed gas

$\left[\mathrm{m} \cdot \mathrm{s}^{-1}\right]$

$y_{i} \quad$ mole fraction of species $i$

[-]

Z $\quad$ space coordinates

[m]

\section{GREEK LETTERS}

$\alpha_{i} \quad$ constant parameter of species $i$

$\varepsilon_{\mathrm{B}} \quad$ bed void fraction

$\varepsilon_{\mathrm{T}} \quad$ overall void fraction

$\theta_{\mathrm{PW}} \quad$ weight fraction of paraffin wax

$\lambda_{\mathrm{B}}$ axial thermal conductivity of packed bed

$\lambda_{\mathrm{W}}$ axial thermal conductivity of column wall
$[-]$

$\left[\mathrm{kg}-\mathrm{PW} \cdot \mathrm{kg}-\mathrm{PCM}^{-1}\right]$

$\left[\mathrm{J} \cdot \mathrm{m}^{-1} \cdot \mathrm{s}^{-1} \cdot \mathrm{K}^{-1}\right]$

$\left[\mathrm{J} \cdot \mathrm{m}^{-1} \cdot \mathrm{s}^{-1} \cdot \mathrm{K}^{-1}\right]$ 


$\begin{array}{cll}\mu & \text { dynamic viscosity of fluid } & {[\mathrm{Pa} \cdot \mathrm{s}]} \\ \rho & \text { density of fluid } & {\left[\mathrm{kg} \cdot \mathrm{m}^{-3}\right]} \\ \rho_{\mathrm{B}} & \text { bed density of activated carbon and PCM } & {\left[\mathrm{kg}-(\mathrm{AC} \& \mathrm{PCM}) \cdot \mathrm{m}^{-3}\right]} \\ \rho_{\mathrm{P}, \mathrm{AC}} & \text { particle density of activated carbon } & {\left[\mathrm{kg}-\mathrm{AC} \cdot \mathrm{m}^{-3}\right]} \\ \rho_{\mathrm{M}, \mathrm{AC}} & \text { material density of activated carbon } & {\left[\mathrm{kg}-\mathrm{AC} \cdot \mathrm{m}^{-3}\right]} \\ \rho_{\mathrm{P}, \mathrm{PCM}} & \text { particle density of PCM } & {\left[\mathrm{kg}-\mathrm{AC} \cdot \mathrm{m}^{-3}\right]} \\ \phi^{\mathrm{ul}} & \text { upper limit of weight fraction of PCM } & {[\mathrm{kg}-\mathrm{PCM} \cdot \mathrm{kg}-} \\ & & \left.(\mathrm{AC} \& \mathrm{PCM})^{-1}\right] \\ \phi^{\text {opt }} & \begin{array}{l}\text { optimum weight fraction of PCM in adiabatic adsorption } \\ \text { process }\end{array} & {\left[\mathrm{kg}-\mathrm{PCM} \cdot \mathrm{kg}^{-}\right.} \\ \phi_{\mathrm{PCM}} & \text { weight fraction of PCM } & \left.(\mathrm{AC} \& \mathrm{PCM})^{-1}\right] \\ & & {[\mathrm{kg}-\mathrm{PCM} \cdot \mathrm{kg}-} \\ \chi_{i} & \text { constant parameter of species } i & \left.(\mathrm{AC} \& \mathrm{PCM})^{-1}\right]\end{array}$

TOC

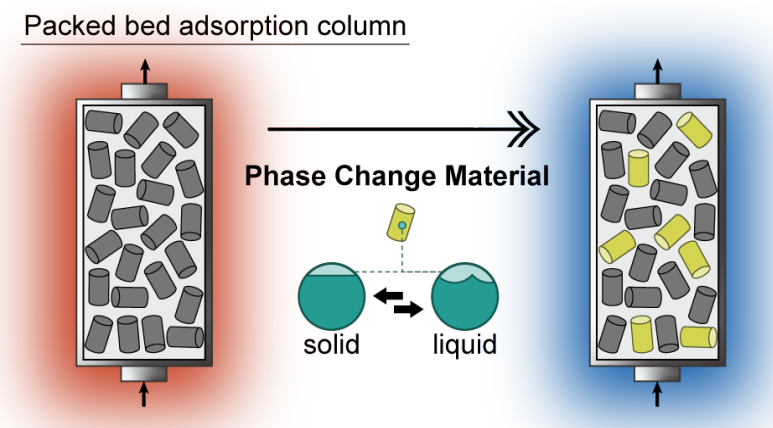

\section{REFERENCES}

1. Sholl, D. S.; Lively, R. P., Seven chemical separations to change the world. Nature 2016, $532,435-437$. 
2. Shafeeyan, M. S.; Wan Daud, W. M. A.; Shamiri, A., A review of mathematical modeling of fixed-bed columns for carbon dioxide adsorption. Chem. Eng. Res. Des. 2014, 92 (5), 961-988.

3. Liu, Y.; Ritter, J. A.; Kaul, B. K., Simulation of gasoline vapor recovery by pressure swing adsorption. Sep. Purif. Technol. 2000, 20 (1), 111-127.

4. Chai, S. W.; Kothare, M.; Sircar, S., Rapid Pressure Swing Adsorption for Reduction of Bed Size Factor of a Medical Oxygen Concentrator. Ind. Eng. Chem. Res. 2011, 50, 8703-8710.

5. Lopes, F. V. S.; Grande, C. A.; Rodrigues, A. E., Fast-cycling VPSA for hydrogen purification. Fuel 2012, 93, 510-523.

6. Vemula, R. R.; Sircar, S., Comparative performance of an adiabatic and a nonadiabatic PSA process for bulk gas separation - a numerical simulation. AlChE J. 2017, 63 (9), 4066-4078.

7. Yang, R. T.; Cen, P. L., Improved pressure swing adsorption processes for gas separation: by heat exchange between adsorbers and by using high-heat-capacity inert additives. Ind. Eng. Chem. Proc. Design Devel. 1986, 25 (1), 54-59.

8. Farooq, S.; Hassan, M. M.; Ruthven, D. M., Heat effects in pressure swing adsorption systems. Chem. Eng. Sci. 1988, 43 (5), 1017-1031.

9. Sharma, A.; Tyagi, V. V.; Chen, C. R.; Buddhi, D., Review on thermal energy storage with phase change materials and applications. Renew. Sust. Energ. Rev. 2009, 13 (2), 318-345.

10. Vasiliev, L.; Larisa, K.; A.G, K.; Mishkinis, D.; A.M, S.; N.K, L., Activated carbon fiber composites for ammonia, methane and hydrogen adsorption. Int. J. Low Carbon Technol. 2006, 1 (2) 95-111. 
11. Dincer, I.; Dost, S.; Li, X., Performance analyses of sensible heat storage systems for thermal applications. Int. J. Energy Res. 1997, 21 (12), 1157-1171.

12. Pacheco, J.; Showalter, S.; Kolb, W., Development of a Molten-Salt Thermocline Thermal Storage System for Parabolic Trough Plants. J. Sol. Energy Eng. 2002, 124, 153.

13. Regin, A. F.; Solanki, S. C.; Saini, J. S., Heat transfer characteristics of thermal energy storage system using PCM capsules: A review. Renew. Sust. Energ. Rev. 2008, 12 (9), 2438-2458.

14. Toledo, M.; Rojas, C.; Montes, E.; Veloso, J.; Sáez, A., Use of phase change materials on an adsorbed carbon dioxide storage system. Appl. Therm. Eng. 2013, 51 (1), 512-519.

15. Li, X.; Li, Y., Applications of organic phase change materials embedded in adsorbents for controlling heat produced by charging and discharging natural gas. Adsorption 2015, 21 (5), 383389.

16. Horstmeier, J. F.; Gomez Lopez, A.; Agar, D. W., Performance improvement of vacuum swing adsorption processes for $\mathrm{CO} 2$ removal with integrated phase change material. Int. J. Greenh. Gas Control 2016, 47, 364-375.

17. Choi, J.; Yoshie, K.; Moteki, T.; Ogura, M., Theoretical Evaluation of an Organic Phase Change Material (PCM)-Inserted Dual-Functional Adsorbent for the Recovery of Heat of Adsorption. Ind. Eng. Chem. Res. 2019, 58 (23), 10114-10118.

18. Seki, K. Adsorbent of latent-heat storage type for canister and process for producing the same. WO03/106833, 2003. 
19. Malek, A.; Farooq, S., Study of a six-bed pressure swing adsorption process. AlChE J. 1997, 43 (10), 2509-2523.

20. Park, J.-H.; Kim, J.-N.; Cho, S.-H.; Kim, J.-D.; Yang, R. T., Adsorber dynamics and optimal design of layered beds for multicomponent gas adsorption. Chem. Eng. Sci. 1998, 53 (23), 3951-3963.

21. Kim, M.-B.; Bae, Y.-S.; Choi, D.-K.; Lee, C.-H., Kinetic Separation of Landfill Gas by a Two-Bed Pressure Swing Adsorption Process Packed with Carbon Molecular Sieve: Nonisothermal Operation. Ind. Eng. Chem. Res. 2006, 45 (14), 5050-5058.

22. Dantas, T. L. P.; Luna, F. M. T.; Silva, I. J.; de Azevedo, D. C. S.; Grande, C. A.; Rodrigues, A. E.; Moreira, R. F. P. M., Carbon dioxide-nitrogen separation through adsorption on activated carbon in a fixed bed. Chem. Eng. J. 2011, 169 (1), 11-19.

23. Lopes, F. V. S.; Grande, C. A.; Rodrigues, A. E., Activated carbon for hydrogen purification by pressure swing adsorption: Multicomponent breakthrough curves and PSA performance. Chem. Eng. Sci. 2011, 66 (3), 303-317.

24. Ribeiro, R.P.P. L.; Grande, C. A.; Rodrigues, A. E., Adsorption of Water Vapor on Carbon Molecular Sieve: Thermal and Electrothermal Regeneration Study. Ind. Eng. Chem. Res. 2011, 50 (4), 2144-2156.

25. Casas, N.; Schell, J.; Pini, R.; Mazzotti, M., Fixed bed adsorption of CO2/H2 mixtures on activated carbon: experiments and modeling. Adsorption 2012, 18 (2), 143-161. 
26. Marx, D.; Joss, L.; Hefti, M.; Mazzotti, M., Temperature Swing Adsorption for Postcombustion CO2 Capture: Single- and Multicolumn Experiments and Simulations. Ind. Eng. Chem. Res. 2016, 55 (5), 1401-1412.

27. Schumann, T. E. W., Heat transfer: A liquid flowing through a porous prism. J. Franklin Inst. 1929, 208 (3), 405-416.

28. Ismail, K. A. R.; Stuginsky Jr, R., A parametric study on possible fixed bed models for pcm and sensible heat storage. Appl. Therm. Eng. 1999, 19 (7), 757-788.

29. Ismail, K. A. R.; Henrı́ quez, J. R., Numerical and experimental study of spherical capsules packed bed latent heat storage system. Appl. Therm. Eng. 2002, 22 (15), 1705-1716.

30. de Gracia, A.; Cabeza, L. F., Numerical simulation of a PCM packed bed system: A review. Renew. Sust. Energ. Rev. 2017, 69, 1055-1063.

31. Regin, A. F.; Solanki, S. C.; Saini, J. S., An analysis of a packed bed latent heat thermal energy storage system using PCM capsules: Numerical investigation. Renew. Energ. 2009, 34 (7), $1765-1773$.

32. van Leer, B., Towards the ultimate conservative difference scheme. II. Monotonicity and conservation combined in a second-order scheme. J. Comput. Phys. 1974, 14 (4), 361-370.

33. Hindmarsh, A. C.; Brown, P. N.; Grant, K. E.; Lee, S. L.; Serban, R.; Shumaker, D. E.; Woodward, C. S., SUNDIALS: Suite of nonlinear and differential/algebraic equation solvers. ACM Trans. Math. Softw. 2005, 31 (3), 363-396. 
34. Myers, A. L.; Prausnitz, J. M., Thermodynamics of mixed-gas adsorption. AlChE J. 1965, 11 (1), 121-127. 